\title{
Design and testing of conductive polysilicon beam leads for use in a high-density biomedical connector
}

\author{
Stefan Nikles $^{1,2}$, Robert Bradley ${ }^{3}$, Sanford Bledsoe $^{4}$ \\ and Khalil Najafi ${ }^{1,2}$ \\ ${ }^{1}$ Center for Wireless Integrated Microsystems, University of Michigan, 2609 Draper Road, \\ Ann Arbor, 48109 MI, USA \\ ${ }^{2}$ Department of Biomedical Engineering, University of Michigan, 2200 Bonisteel Blvd., \\ Ann Arbor, 48109 MI, USA \\ ${ }^{3}$ Department of Biological \& Materials Sciences, School of Dentistry, University of \\ Michigan, 1011 N. University, Ann Arbor, 48109 MI, USA \\ ${ }^{4}$ Department of Otolaryngology, University of Michigan, 1500 E. Medical Center Drive, \\ Ann Arbor, 48109 MI, USA \\ E-mail: nikles@umich.edu
}

Received 19 December 2003

Published 20 May 2004

Online at stacks.iop.org/JMM/14/957

DOI: $10.1088 / 0960-1317 / 14 / 7 / 017$

\begin{abstract}
A study was conducted to measure and characterize the reliability of polysilicon cantilever beams with electroplated gold pads for use in a high-density biomedical connector. In this design, an array of beams is brought into contact with a corresponding array of $30 \mu \mathrm{m}$ high gold bumps, forming electrical connection. Analytical computations of multi-layer beams were performed, including the effects of residual stresses. Beam leads of various lengths and widths with electroplated gold contact pads on their ends were tested over 1000 cycles to determine their mechanical reliability, and to measure their contact resistance with gold bumps on a separate substrate. The dimensions of the polysilicon beam that produce the least breakage were determined to be $400 \mu \mathrm{m}$ long by $125 \mu \mathrm{m}$ wide. For a beam having a calculated contact force of $\sim 100 \mu \mathrm{N}$, the initial contact resistance was $764 \mathrm{~m} \Omega$. After 1000 connect/disconnect cycles, beams of this type had an average final contact resistance of $1.598 \Omega$. These results demonstrate that very high-density connectors with high mechanical reliability and low-contact resistance can be fabricated.
\end{abstract}

(Some figures in this article are in colour only in the electronic version)

\section{Introduction}

For many biomedical and microsystems applications, a reliable connector is needed to provide an interface between an implanted device and external electronics. In biomedical systems, the connector is used to link internally implanted microsensors such as micromachined neural probes to the outside world. These applications are particularly demanding due to the limitations presented by animal size and the biological environment. A connector must be small (on the order of a few millimeters), have many interconnect leads, tolerate exposure to biological fluids and debris, withstand repeated connect/disconnect cycles, and have a lowcontact resistance and cross-talk between channels. 'Pin-andhole' connectors such as those produced by Microtek, Inc. (Chicopee, MA, USA) or Omnetics Connector Corporation (Minneapolis, MN, USA) have been the standard for neural probes in the past. Although mechanically strong and electrically stable, they are large and cannot be scaled down in size easily. 


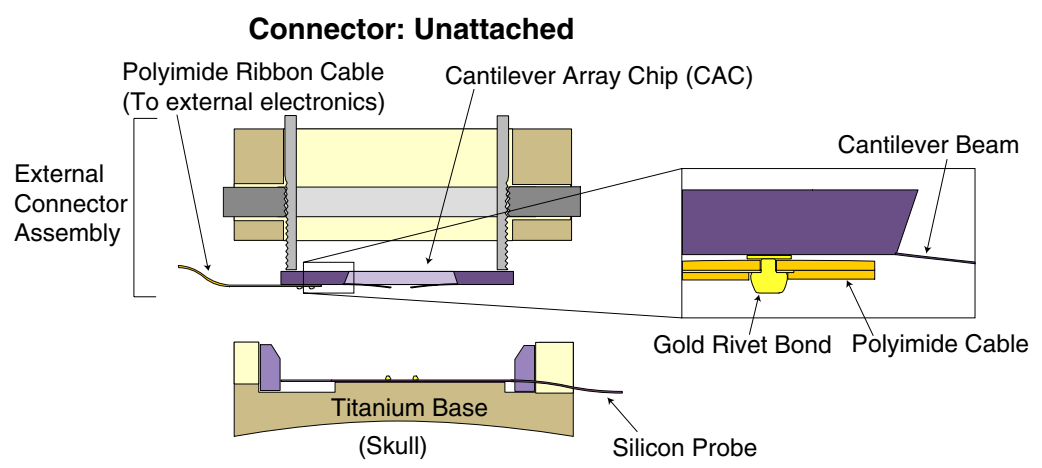

Connector: Attached

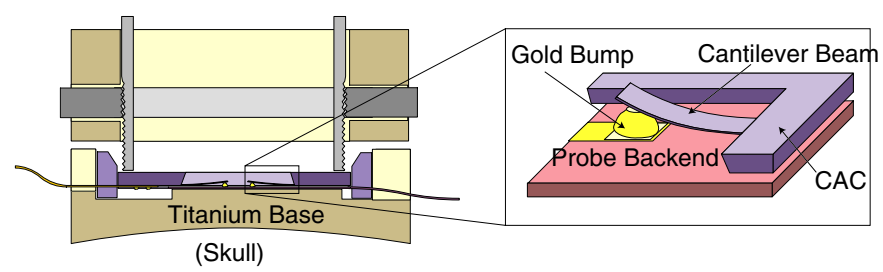

Figure 1. Schematic of a high-density connector using polysilicon cantilever beams.

As an alternative, we have approached the problem of reducing connector size by utilizing technology found in micromachined probe cards. Probe cards are capable of simultaneously forming thousands of electrical contacts to various test points on a silicon chip, allowing a circuit to be quickly tested. One version of a micromachined probe card uses a flexible polyimide diaphragm with metal contact pads on it. The polyimide diaphragm is lowered on top of the circuit and deflected downward using air pressure [1]. Other versions use micromachined cantilever beams to probe the circuit. Most designs simply lower the beams onto the structure [2, 3], while others have fabricated thermally actuated beams for independent control over forming electrical contacts [4].

We previously reported a high-density connector similar to [1], where a polyimide diaphragm with 32 gold pads was forced to contact corresponding pads on the backend of an implantable microprobe using an external vacuum [5]. The advantage of this design was that it was produced using microfabrication techniques, allowing the production of a much smaller connector. In this design the pads were mechanically coupled together by the diaphragm however. Any irregularities in the mating surface (e.g., dust, epoxy) would keep several adjacent channels from making contact. Furthermore, the need for the external vacuum line for pressure actuation complicated the connector.

A new connector system under development is similar to that used by Park et al [3] in that an electrical connection between the two components is formed by bringing an array of conductive cantilever beams in contact with pads on the opposing surface. In [3] these beams are machined out of (111)-orientation bulk silicon. In our design, the cantilever beams are made out of phosphorous-doped polysilicon, and are brought into contact with a corresponding array of gold bumps approximately $30 \mu \mathrm{m}$ high on the other connector half, shown in figure 1 [6]. The advantage of this design is that the polysilicon beams are much more flexible than bulk silicon beams, and may therefore be made much smaller without breakage occurring during deflection.

This design will use a cantilever array chip (CAC) containing 32 polysilicon cantilever beams with electroplated gold contacts on their ends. The gold-bump array may be placed on the backend of any micromachined neural probe $[7,8]$. An external connector assembly containing the CAC is manually attached to the titanium base using a clip. Then a screw is used to mechanically lower the CAC down on top of the probe backend. This allows for better control and reduces the chance that the beams may be broken by rough handling. As the two pieces are brought together, the bumps force the beams to deflect, and form an electrical connection between each bump-beam pair. Electrical signals may pass to or from the gold bumps, through the cantilever beams to bond pads on the backend of the CAC, where a polyimide ribbon cable may be attached for access to external electronics using gold rivet bonds [9]. When a testing session is complete, the CAC is simply removed and a protective cover is placed over the gold-bump array. A connector housing containing a micromachined alignment chip lines up the CAC to the probe during attachment and holds the two pieces together during testing.

This design has the advantage of being unaffected by unevenness in the mating surface, since the beams may deflect independently. This design is also beneficial to micromachined neural probe users. Current research in probe technology emphasizes integrating active circuits on the backends of probes $[10,11]$. This is advantageous because relatively weak neural signals may be amplified close to their source, thus reducing noise. Multiplexers may also be used to increase probe functionality. However, integrating active circuits on silicon probes complicates the fabrication process and typically reduces their yield. Furthermore, if an on-probe circuit should fail while implanted, the probe and headcap 

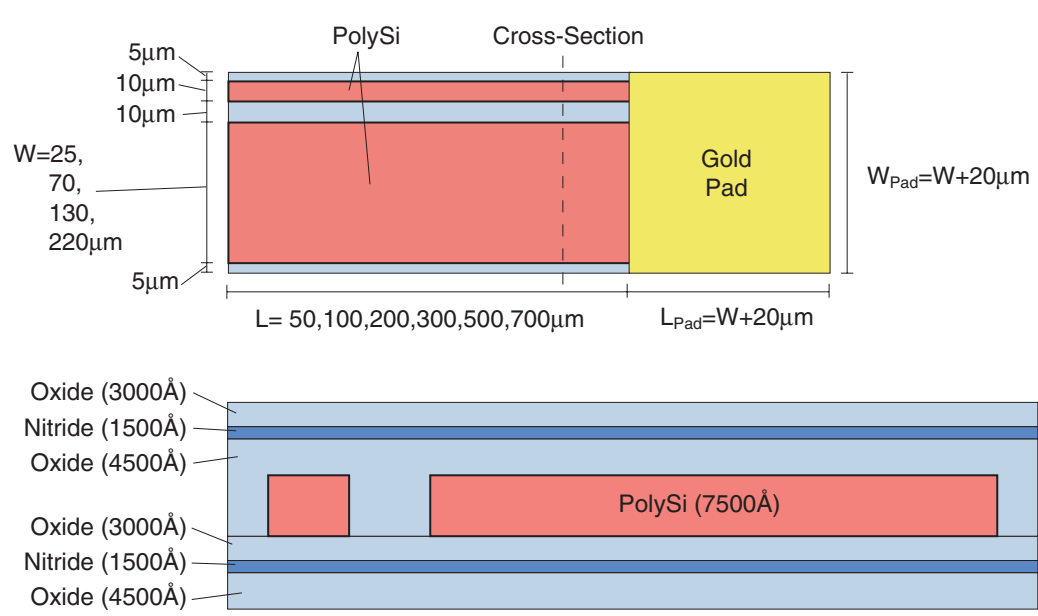

Figure 2. Top view and cross-sectional diagram of the cantilever beam showing some of the dimensions used in fabrication. Each beam has two polysilicon leads for 4-point measurement of the contact resistance (opposing connector half also had two leads at its contact). The larger of the two leads supplied current and the smaller one was used to measure the voltage drop across the contact.

Table 1. Properties of the materials used for the beams in this study. Properties marked with an asterisk $\left(^{*}\right)$ were measured at the UM Solid-State Electronics Laboratory.

\begin{tabular}{lccccc}
\hline Material & $\begin{array}{l}\text { Young's modulus } \\
(\mathrm{GPa})\end{array}$ & $\begin{array}{l}\text { Internal stress } \\
(\mathrm{MPa})\end{array}$ & Fracture strength & $\begin{array}{l}\text { Density } \\
\left(\mathrm{kg} \mathrm{m}^{-3}\right)\end{array}$ & $\begin{array}{l}\text { Poisson's } \\
\text { ratio }\end{array}$ \\
\hline Silicon dioxide $\left(\mathrm{SiO}_{2}\right)$ & $75[29]$ & $-193(\mathrm{C})^{*}$ & $486.08 \mathrm{MPa}[30]$ & $2200[31]$ & $0.17[32]$ \\
Silicon nitride $\left(\mathrm{Si}_{3} \mathrm{~N}_{4}\right)$ & $290[33]$ & $+1000(\mathrm{~T})^{*}$ & $14.06 \mathrm{GPa}[29]$ & $3100[31]$ & $0.24[30]$ \\
Polysilicon & $165.6[34]$ & $-316(\mathrm{C})^{*}$ & $1.20 \mathrm{GPa}[23]$ & $2330[30]$ & $0.22[23]$ \\
\hline
\end{tabular}

must be replaced or the experiment must be terminated. As an alternative, the active circuitry may be integrated on the cantilever array chip, or added as part of a multi-chip module. This simplifies the probe fabrication process and, should a circuit fail on the $\mathrm{CAC}$, it may be easily replaced without affecting the animal subject.

This paper discusses the design and testing of polysilicon cantilever beams for use in a high-density connector. To minimize connector size, we desire beams as small as possible. However, the beams must not be so short that they will break when deflected by the gold ball bumps. In addition, the axial contact force generated by the deflection of the beam should be great enough to achieve a quality metallic contact to the gold bump. An analytical model was developed to predict the stresses and the resultant force in a composite beam for a given deflection. Furthermore, the reliability of the polysilicon beams was examined empirically after repeated usage. The contact resistance of the gold pads was also studied as a function of both usage and force.

\section{Polysilicon beam design}

The cantilever beams used in the high-density connector are designed to be compatible with the University of Michigan passive neural probe process, described in [12]. Compatibility with this process is important since this makes it possible to fabricate both cantilever array chips and neural probes at the same time. These neural probes consist of a thin silicon body 3-15 $\mu \mathrm{m}$ thick, defined by a heavy boron diffusion. On top there exists a patterned layer of conductive polysilicon leads, insulated on top and bottom by three layers of dielectrics (silicon dioxide/silicon nitride/silicon dioxide). Recording sites are created by etching through the top layer of dielectrics to the polysilicon, then coating the sites with a suitable electrode material such as iridium. The beams on the CAC, which are supported on a silicon wafer substrate, are identical to the flexible neural probes in that they consist of a conductive polysilicon layer surrounded by three insulating layers of silicon dioxide, silicon nitride and silicon dioxide on both sides (figure 2). The main difference is that the beams do not have a boron-diffused silicon region underneath. Although the CAC is not intended to be in continuous contact with bodily fluids, it is reasonable to assume that it will be incidentally exposed to some fluids during normal usage, and that these fluids will remain there until they dry or are cleaned off. The dielectric triple layer has been shown to sufficiently insulate neural probes in long-term saline soak tests $[13,14]$ and should be more than sufficient to protect the polysilicon beams and interconnects during this brief exposure.

The materials used in the fabrication of the cantilever array will typically have significant residual stresses remaining from fabrication. Ideally these stresses are minimized, but they can never be completely eliminated. In general silicon dioxide is compressive, while silicon nitride is tensile (table 1). The thickness of each layer may be chosen so that the stresses are balanced, and the dielectric layer as a whole exerts no net tensile or compressive forces on the beam. Silicon nitride has a tensile stress approximately five times greater in magnitude than the compressive stress in silicon dioxide. As a consequence, the current University of Michigan passive probe process calls for the net oxide thickness to be five times greater than the nitride layer thickness (table 2).

Failure mechanisms for the beams must be considered as well. Schweitz and co-workers have described how the effective fracture strength of a material in a beam may vary 
Table 2. Dimensions used for the beams in this study. Total width for the polysilicon layer represents the sum of the two leads in the beam (figure 2).

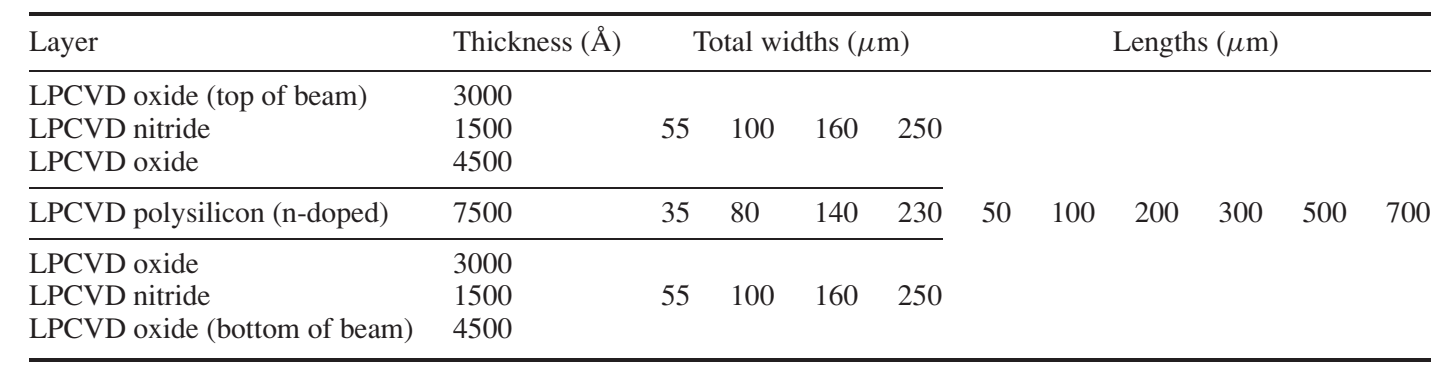

based on the origin of the crack and the properties of the material used to coat the beam $[15,16]$. They demonstrated that oxide-coated beams will actually have significantly higher fracture strengths than uncoated beams. It will be assumed in this study that the coatings have no positive effect on the fracture strength of the underlying layer however. This results in a conservative estimate of the fracture strength, suitable for design purposes. Schmitt et al have also investigated failures due to mechanical stress (cracking, delamination, etc) as well as chemical reactions with the surrounding liquid (adsorption/desorption, corrosion, etc) [17]. As mentioned above, it is not expected that the beams on the CAC will be exposed to biological fluids for any period long enough to cause any deterioration in the beam. Only mechanical failure modes are therefore considered. Furthermore, the materials used in the cantilever beams are brittle and tend to be weaker in tension than compression. For modeling purposes, we will only consider beam failure due to the tensile stress in each layer. That is, once the material is stressed beyond its tensile fracture strength, micro-cracks may form. As these cracks propagate, the beam weakens and total failure usually follows. While this is an over-simplification of the beam failure mechanism, it gives us a general idea about how the beams will behave when deflected.

Despite efforts to balance the stresses in the beam, each layer will still have some residual stress after the beams have been released. These residual stresses reduce the overall amount of bending a beam will tolerate before breaking. Therefore, it is important to develop a relationship between the minimum length of the beam and the deflection of the beam, given the presence of residual stresses. Analysis of the stresses in the beam was performed using the principles outlined in [18]. When the beam is fabricated, residual stresses will form in each layer. Once released, the beam will relax in such a way that there will be no net force acting along the length of the beam, and no net moment on the beam. For a beam with $N$ layers:

$$
\begin{aligned}
\sum_{i}^{N} F_{i} & =\sum_{i}^{N} \int \sigma_{i}(z) \mathrm{d} A=0 \\
\sum_{i}^{N} M_{i} & =\sum_{i}^{N} \int \sigma_{i}(z) z \mathrm{~d} A=0
\end{aligned}
$$

where $\sigma_{i}(z)$ is the stress in layer $i$ of the beam, and $z$ is the distance from the neutral axis. The relaxation of the beam can be considered as a two-step process. It first relaxes along the lengthwise direction, redistributing the stresses so that $(1 a)$ is satisfied. Then the beam will curl, further modifying the stresses so that $(1 b)$ is satisfied.

Stress due to relaxation in the longitudinal direction only. Prior to release, the residual stress in layer $i$ may be written as

$$
\sigma_{\mathrm{res}, i}=\left[\frac{L}{L_{o, i}}-1\right] E_{i}^{\prime} \rightarrow L_{o, i}=\frac{L E_{i}^{\prime}}{\sigma_{\mathrm{res}, i}+E_{i}^{\prime}}
$$

where $L$ is the designed beam length and $L_{o, i}$ is the length layer $i$ would have if it were allowed to completely relax so that it had no stress in it, independent of the other layers. Young's modulus $\left(E_{i}\right)$ has been modified for biaxial stress:

$$
E_{i}^{\prime}=\frac{E_{i}}{1-v_{i}}
$$

where $v_{i}$ is Poisson's ratio for layer $i$. Biaxial stress is assumed since the residual stress acts in the $x$ and $y$ directions.

The stress in the beam after it has relaxed longitudinally to a length of $L_{r}$ is

$$
\sigma_{l, i}=\left[\frac{L_{r}}{L_{o, i}}-1\right] E^{\prime} .
$$

Substitution of this equation into ( $1 a)$, and substituting for $L_{o, i}$ with (2) gives the longitudinally relaxed stress of each layer in the beam:

$$
\sigma_{l, i}=\frac{\sigma_{\mathrm{res}, i} \sum_{j} A_{j} E_{j}^{\prime}-E_{i}^{\prime} \sum_{j} A_{j} \sigma_{\mathrm{res}, j}}{\sum_{j} A_{j}\left(\sigma_{\mathrm{res}, j}+E_{j}^{\prime}\right)}
$$

where $A_{j}$ is the cross-sectional area of layer $j$.

Stress due to bending. For a beam with an applied force $F$ on the end of the beam, length $L$, and already having stresses $\sigma_{l, i}$ in each layer, $(1 b)$ gives

$\sum_{i} M_{i}=F(L-x)+\sum_{i} \sigma_{l, i} z_{c m, i} A_{i}-\kappa \sum_{i} E_{i} I_{i}=0$

where $z_{c m, i}$ is the distance of the centroid of layer $i$ from the neutral axis. The third term in the middle of the equation is the product of the beam curvature $\kappa$ and the flexural rigidity. Note that the unmodified Young's modulus is used here since the beam is considered to bend in only one direction (no biaxial strain caused by bending). The moment of inertia for layer $i\left(I_{i}\right)$ is taken with respect to the neutral axis of the beam. Solving for $\kappa$ gives

$$
\kappa=\frac{F(L-x)+\sum_{i} \sigma_{l, i} z_{c m, i} A_{i}}{\sum_{i} E_{i} I_{i}} .
$$

The stress due to bending in layer $i$ is simply

$$
\sigma_{b, i}=-E_{i} \kappa z=\frac{E_{i} z}{\sum_{i} E_{i} I_{i}}\left[F x-F L-\sum_{i} \sigma_{l, i} z_{c m, i} A_{i}\right] \text {. }
$$


Polysilicon beam lead design and testing

Total stress. The total stress at the base of the beam $(x=0)$ in each layer $i$ of the beam is the sum of the longitudinally relaxed stress and the bending stress:

$\sigma_{\mathrm{tot}, i}=\sigma_{l, i}+\sigma_{b, i}=\sigma_{l, i}-\frac{E_{i} z}{\sum_{i} E_{i} I_{i}}\left[F L+\sum_{i} \sigma_{l, i} z_{c m, i} A_{i}\right]$.

Substitution of (9) into ( $1 a)$ and ( $1 b)$ confirms that there is no net force or moment acting on the beam once the beam has completely relaxed.

Force versus deflection. The curvature of the beam is simply the second derivative of the beam deflection. Thus, the deflection of the beam end may be found by integrating the equation for curvature twice, or

$\delta_{\max }=\iint \kappa \mathrm{d} x^{2}=\frac{F L^{3}}{3 \sum_{i} E_{i} I_{i}}+\frac{\sum_{i} \sigma_{l, i} z_{c m, i} A_{i}}{2 \sum_{i} E_{i} I_{i}} L^{2}$

(for $x=L$ ).

Solving (10) for $F$ yields

$$
F=\frac{3 \delta_{\max } \sum_{i} E_{i} I_{i}}{L^{3}}-\frac{3 \sum_{i} \sigma_{l, i} z_{c m, i} A_{i}}{2 L}
$$

which represents the force a composite beam develops when it is deflected by a known amount, $\delta_{\max }$.

Stress versus deflection. Finally, the stress in each layer versus the beam deflection may be determined by substitution of (11) into (9):

$$
\sigma_{\mathrm{tot}, i}=\sigma_{l, i}-E_{i} z\left[\frac{3 \delta_{\max }}{L^{2}}-\frac{\sum_{j} \sigma_{l, j} z_{c m, j} A_{j}}{2 \sum_{j} E_{j} I_{j}}\right]<\sigma_{\text {fract }, i}
$$

where $\sigma_{\text {fract }, i}$ is the tensile fracture strength for the material in layer $i$ (a positive value). It is assumed that the materials in this beam are not plastic. The first term in (12) gives the stress after the beam has been allowed to relax longitudinally (no bending). The first term in the brackets gives the contribution of stress due to deflection of the beam. The last term in the brackets is the modification of the stress due to relaxation by curling.

Solving (12) for $L$ gives

$$
L>\sqrt{\frac{3 \delta_{\max }}{\frac{\sum_{j} \sigma_{l, j} z_{c m, j} A_{j}}{2 \sum_{j} E_{j} I_{j}}+\frac{\sigma_{l, i}-\sigma_{\mathrm{fract}, i}}{E_{i} z}}} .
$$

Equation (13) gives the minimum length a specific layer in a beam may have before the tensile stress in that layer exceeds its fracture point for a given deflection. The materials used in these beams are brittle and assumed to fail in tension rather than compression. The layer $i$ whose parameters $\left(E_{i}, \sigma_{l, i}, \sigma_{\text {fract }, i}\right.$, etc) yield the longest minimum length will determine the minimum overall length of the beam.

The beams used in this study are multi-layered, consisting of $7500 \AA$ n-doped polysilicon with insulating dielectric layers of LPCVD silicon oxide/nitride/oxide (4500 $\AA / 1500 \AA /$ $3000 \AA$ ) on both the top and bottom of each beam. As mentioned above, these materials were chosen for their

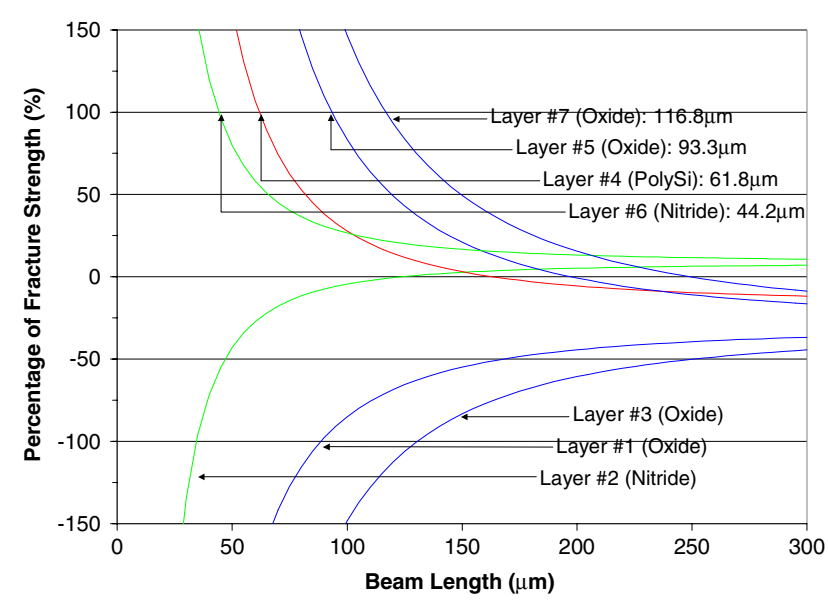

Figure 3. Calculated stresses versus beam length for each layer in the beam, assuming a $-30 \mu \mathrm{m}$ deflection (downward). Stresses are normalized with respect to the fracture strength of the material in each layer. The calculated stress in a layer exceeds the fracture point at the length indicated by the arrow. Positive percentages indicate tensile stresses; negative percentages, compressive stresses.

compatibility with the University of Michigan neural probe fabrication process [12]. Tables 1 and 2 give some of the material properties and dimensions of the beams used in this study. When possible, material properties were obtained from our own facility. Otherwise, we chose values based on materials that had been prepared in as similar a fashion as possible to those used in this study (see fabrication procedure in the following section and table 1). When this was done, attempts were made to choose values representative of the materials over the entire range of preparation conditions.

The beams used in this connector design must deflect downward (into the plane of the CAC) by $-30 \mu \mathrm{m}$. Equation (12) may be used to calculate the stress in each layer as a function of beam length and deflection. As mentioned above, beam fracture is assumed to occur when one or more of the layers reaches its maximum stress limit. This results in a conservative estimate of beam length, acceptable for our purposes. For a downward deflection of $-30 \mu \mathrm{m}$, figure 3 shows that as the length of the beam is decreased, the first layer to reach $100 \%$ of its fracture strength will be the top oxide layer. Calculations show that it reaches its tensile stress limit of $+486 \mathrm{MPa}$ when the beam length goes below $116.8 \mu \mathrm{m}$. Using the assumption stated above, breakage of the entire beam may soon follow if this layer were to fracture. Thus, the minimum length of the beam should be greater than $116.8 \mu \mathrm{m}$.

Equation (11) predicts the contact force that will develop for downward deflection of $-30 \mu \mathrm{m}$, as a function of beam length. According to [19], a force of $100 \mu \mathrm{N}$ should give a contact resistance of approximately 80-200 $\mathrm{m} \Omega$, sufficient for most connector applications. Table 3 gives calculated contact forces as a function of beam length. It shows that the beams must be shorter than 200-300 $\mu \mathrm{m}$ to generate a contact force greater than $100 \mu \mathrm{N}$. However, this assumes that the contacts are clean and free of debris. The contact resistance may therefore be much higher in a biomedical connector that has been subjected to biological fluids. 

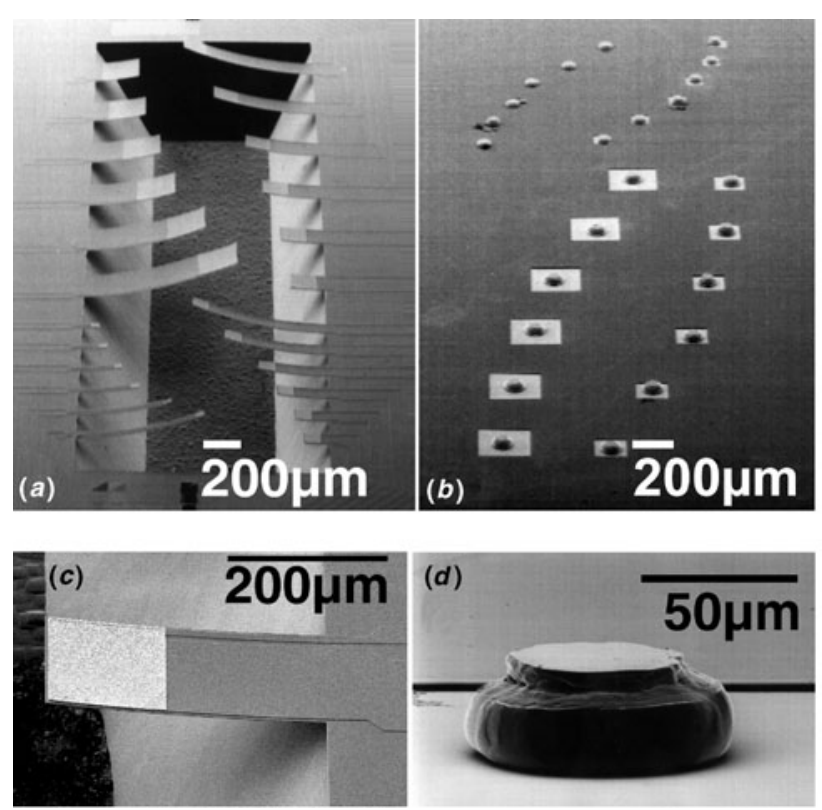

Figure 4. SEM micrographs of the polysilicon cantilever array $(a)$, corresponding glass piece with gold bumps $(b)$, and close-ups of the cantilever beams and gold bump $((c)$ and $(d)$, respectively).

Table 3. Contact forces $(\mathrm{mN})$ generated at the end of the beams having various lengths and widths for $\mathrm{a}-30 \mu \mathrm{m}$ (downward) deflection. Values were calculated analytically. Values greater than $100 \mu \mathrm{N}$ are given in bold type.

\begin{tabular}{llrrr}
\hline Poly width $(\mu \mathrm{m})$ & \multicolumn{1}{c}{35} & \multicolumn{1}{c}{80} & \multicolumn{1}{c}{140} & \multicolumn{2}{c}{230} \\
Total width $(\mu \mathrm{m})$ & 55 & 100 & \multicolumn{1}{c}{160} & 250 \\
\hline Length $(\mu \mathrm{m})$ & \multicolumn{4}{c}{ Forces } \\
50 & $\mathbf{5 . 9 8 8}$ & $\mathbf{1 0 . 9 2 6}$ & $\mathbf{1 7 . 5 0 9}$ & $\mathbf{2 7 . 3 8 4}$ \\
100 & $\mathbf{0 . 7 6 7}$ & $\mathbf{1 . 4 0 0}$ & $\mathbf{2 . 2 4 3}$ & $\mathbf{3 . 5 0 8}$ \\
200 & $\mathbf{0 . 1 0 5}$ & $\mathbf{0 . 1 9 2}$ & $\mathbf{0 . 3 0 7}$ & $\mathbf{0 . 4 8 1}$ \\
300 & 0.036 & 0.065 & $\mathbf{0 . 1 0 5}$ & $\mathbf{0 . 1 6 3}$ \\
500 & 0.011 & 0.020 & 0.032 & 0.050 \\
700 & 0.006 & 0.010 & 0.017 & 0.026 \\
\hline
\end{tabular}

\section{Experimental details}

\subsection{Polysilicon beams}

A test structure consisting of an array of polysilicon beams having different lengths and widths (figures $4(a)$ and (c)) was fabricated on a (100)-oriented silicon substrate (cantilever array chip) to determine the appropriate size for the beams used in the connector, as well as investigate how they function. Each beam consists of $7500 \AA$ n-doped polysilicon with insulating dielectric layers of LPCVD silicon oxide/nitride/oxide (4500 $\AA / 1500 \AA /$ $3000 \AA$ ) on both the top and bottom. The oxide was deposited at $920 \pm 10^{\circ} \mathrm{C}, 450 \mathrm{mTorr}$, with a $2: 1$ ratio of nitrous oxide to dichlorosilane. The nitride was deposited at $820 \pm 10{ }^{\circ} \mathrm{C}$, 250 mTorr, with a 4:1 ratio of ammonia to dichlorosilane. The

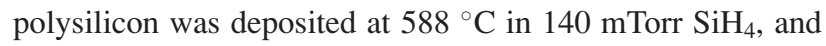
doped using $\mathrm{POCl}_{3}$ at $950{ }^{\circ} \mathrm{C}(30 \mathrm{~min}$ diffusion, $1 \mathrm{~h}$ drivein). The end of the beam has a $2 \mu \mathrm{m}$-thick electroplated gold pad for electrical contact to the opposing connector piece. The size of this contact was not included in the length of the beam, since the gold pad typically does not bend. In the test structure used in this paper, each beam has two separate polysilicon leads running up its length (figure 2). These leads merged at the gold contact pad. The opposing connector half also had two leads running up to the gold ball bump. Together, these leads were used for a 4-point contact resistance measurement between the electroplated gold pad and the gold bump. This is necessary since the resistance of the interconnects and the polysilicon beams leading up to the pads was relatively large. The resistance of the beams themselves ranges from $3.5 \Omega(50 \mu \mathrm{m}$ long $\times$ $230 \mu \mathrm{m}$ wide polysilicon) to $320 \Omega(700 \mu \mathrm{m}$ long $\times 35 \mu \mathrm{m}$ wide polysilicon).

After the pads were electroplated, the beam edges and the area for the underlying trench were defined by etching the dielectrics surrounding the beams, exposing the silicon substrate underneath. The beams were released by etching the wafer with ethylenediamine pyrocatechol (EDP). EDP etches any silicon on the wafer that has not been protected by dielectrics. Furthermore, it will undercut the beams and release them. EDP etches silicon anisotropically, showing preference to the $\langle 100\rangle$ and $\langle 110\rangle$ directions, but not etching in the $\langle 111\rangle$ direction [20]. This process creates a rectangular trench in the substrate, having sloped sidewalls formed by the $\{111\}$ planes. This process is also used to release silicon neural probes [12].

Some upward curvature may be seen in figure $4(c)$. This is due to uneven stresses in the dielectric films surrounding the beam. Equation (10) shows that, even with no applied force, a $200 \mu \mathrm{m}$ long beam will curve upward by $4.0 \mu \mathrm{m}$ due to the residual stresses. The curvature appears to be somewhat larger for these structures, indicating that the stress imbalance in the beam is greater than expected. This curvature is advantageous because it allows the beams to easily contact the bumps on the opposing piece. However, these stresses can increase the overall likelihood of fracture in the beam. Care was therefore taken to ensure these stresses were not too great in the final structure by modifying the LPCVD deposition recipes for the materials. A matching glass piece had a similar arrangement of gold pads patterned on it (figures $4(b)$ and $(d)$ ). A gold bump was formed on top of these pads with a ball-bonder. The tops of the bumps were then flattened using a coining attachment on the bonder, making the bumps $33 \pm 4 \mu \mathrm{m}$ high.

A test setup was constructed that allowed the glass piece to be aligned to the CAC and then repeatedly raised and lowered to form electrical connection between the two pieces. The glass piece was raised and lowered onto the CAC 1000 times, representing a usage of four times a day, 5 days a week, for nearly 1 year. The expected duration of an implanted probe in our studies is typically a few days to roughly 6 months. Electrical connection was determined for each channel by applying a $10 \mathrm{mV}(\sim 10 \mu \mathrm{A})$ signal across the terminals and viewing the output. A frequency of $1 \mathrm{kHz}$ was chosen for the applied voltage because this is the primary frequency component of most neural signals. The voltage was applied prior to making the connection and left on after disconnection. Three CAC's were tested, having beams of each length and width represented twice on each chip.

In addition to determining electrical contact on each trial, the contact resistance at $1 \mathrm{kHz}$ was measured on trials 1,2 , 5,10 , etc. As mentioned above, each pad on both pieces 


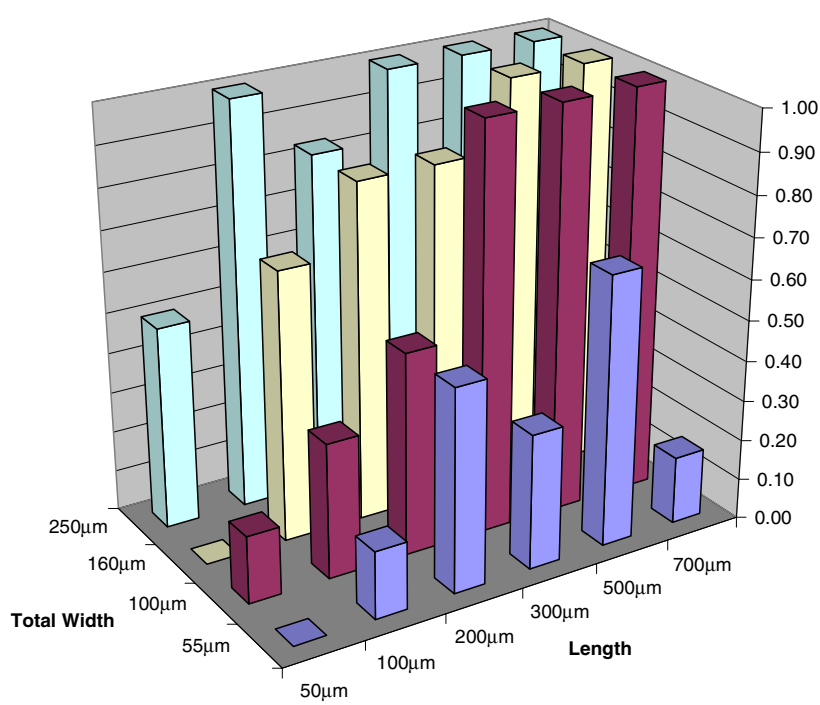

Figure 5. Reliability as a function of length and width of the beam.

had two leads connected to it. After making contact between the two pieces, one lead-pair was used for passing a current through the contact. The other pair of leads was used for measuring the resulting voltage drop across the contact. This allowed measurement of the contact resistance in each channel, eliminating the effects of line resistance. To test the ability of the connector to withstand biological fluids getting on the beams and the subsequent cleaning necessary, the CAC was rinsed with a bovine albumin solution. This was allowed to dry thoroughly, rinsed three times with de-ionized water, and completely dried prior to each contact resistance measurement.

\section{Results and discussion}

Beam reliability (the fraction of beams lasting 1000 trials) was measured as a function of length and width (figure 5). As expected, the longer, wider beams had a greater reliability than the shorter, narrow beams. The reliability seems to drop off considerably as the beams become less than $300 \mu \mathrm{m}$ long and less than $100 \mu \mathrm{m}$ wide, representing two observed modes of failure.

In the first mode, failure was ultimately because the beam was too short and the stress developed during the normal deflection of $-30 \mu \mathrm{m}$ was too great for the beam to withstand. The predicted minimum length was only $116.8 \mu \mathrm{m}$ however, somewhat less than the observed value of $300 \mu \mathrm{m}$. There are several possible explanations for this difference. As previously mentioned, material properties listed in table 1 may be different from the actual properties of the materials used in this study, due to differing preparation conditions. The largerthan-predicted upward curvature of the beams further indicates that the actual properties of these beams differ from values reported in the literature. When possible, measurements were taken from monitor wafers that were adjacent to the device wafers during material deposition. Still, these values may vary from run to run.

Much variance has been reported in the literature as well, based on differing deposition conditions, measurement methods, etc. For instance, the fracture strength of LPCVD polysilicon has been reported as: $2650 \pm 150 \mathrm{MPa}$ [21], $566 \mathrm{MPa}$ [22] and $1200 \pm 150 \mathrm{MPa}$ [23]. We ultimately chose to use the last reference, as it was for n-doped LPCVD polysilicon, doped using PSG, and annealed at $1050{ }^{\circ} \mathrm{C}$ for $1 \mathrm{~h}$. The second reference also closely matched our process parameters, except the polysilicon was doped by ion implantation, which gives a different doping profile than standard diffusion/drive-in doping. Furthermore, stress gradients may develop through the thickness of the materials themselves [24, 25], accounting for significant variations in the breakage of the beams. However, this effect was not considered in the model described in this work. For the purposes of future designs, a correction factor could be assumed when determining the beam length. This would help us to account for any variations in the material properties. In this case, the results suggest that the minimum beam length should be approximately 2.6 times longer than the calculated minimum length.

The second mode of failure was due to large surface tension forces generated during the rinsing and drying of the CAC during testing. These forces tended to pull all of the beams down into the trench of the CAC as the liquid dried around them. For a given length, the wider beams were stiffer and could overcome the surface tension, freeing themselves. The narrow beams, however, were pulled well beyond the design limit of a $30 \mu \mathrm{m}$ deflection and tended to break during this process. This has importance because it is very likely that the beams in the proposed connector will be subjected to fluids. They must be robust enough to withstand these conditions. From these data it appears that a beam $400 \mu \mathrm{m}$ long and $125 \mu \mathrm{m}$ wide would be the smallest possible beam size to use without it breaking during normal usage.

Ultimately, the beam breaks because the stress is too great for it to bear. Both modes of failure described above give the manner in which this stress was created. However, it is also important to determine how this stress brings about a failure. That is, where are the cracks initiated, and in what way? An inspection of the CAC was performed after 1000 trials to better determine the nature of the failure. Breakage of the beam at the point where it joins the substrate appears to be typical for all beams investigated, regardless of their width or length. This of course is where the analytical model predicts that the stress is maximized. Closer examination shows that the beams tended to break $\sim 20 \mu \mathrm{m}$ inward from the point where the beam begins (figure 6). This is because the underlying trench in the silicon substrate was slightly over etched during the EDP step, causing the trench to be $\sim 20 \mu \mathrm{m}$ wider than expected on each side. Although EDP etches silicon in other directions much faster, it still etches silicon in the $\langle 111\rangle$ direction very slowly, making some over etch unavoidable. The result of this over etch is that the dielectrics that define the perimeter of the trench have an overhang of $\sim 20 \mu \mathrm{m}$. The crack in each beam appears to curve inward from the edge of the dielectric overhang, and cross the beam laterally at the point where the beam meets the edge of the underlying trench.

Scanning electron microscopy shows that there also exist cracks that run lengthwise along the beam, located at the step in the top dielectric triple layer created by the underlying polysilicon (figure 7). Schmitt et al have suggested that intrinsic stresses can be induced by substrate topography 


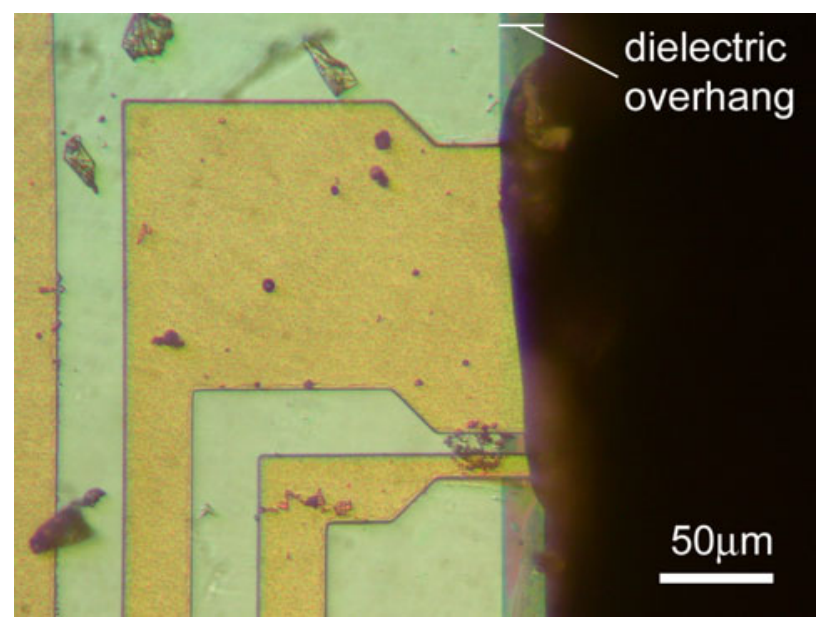

Figure 6. A polysilicon cantilever beam that failed before 1000 trials. Note the inward curvature of the crack from the dielectric overhang.

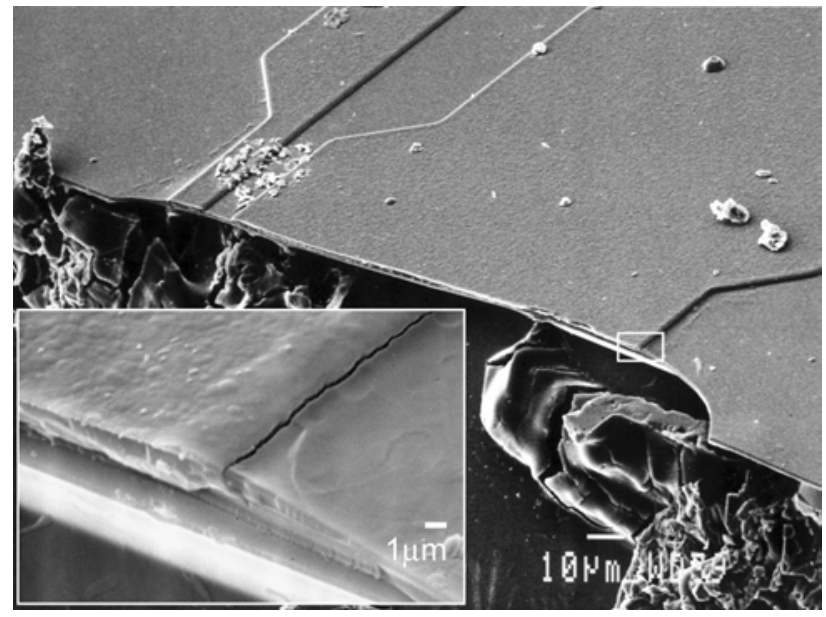

Figure 7. Scanning electron micrograph of a broken beam (same beam as shown in figure 6). Inset: a close-up showing a lengthwise crack running along the edge of polysilicon lead.

[17]. At the edge of the polysilicon, where the dielectrics are deposited over the step, the localized stress may be greater due to variations in growth morphology. It is also possible that the dielectrics at the polysilicon step have a lower fracture strength due to localized deposition variations. The increased residual stress and reduced fracture strength would have the combined effect of allowing the beam to fracture at lower stress levels. This would result in a greater minimum length for a $30 \mu \mathrm{m}$ downward deflection. This may explain why the predicted minimum length of $116.8 \mu \mathrm{m}$ for the beams was less than the observed minimum length of $300 \mu \mathrm{m}$.

In one beam, there was a lateral crack across the base of the beam, but it was incomplete and the beam did not break off (figure 8). This allowed us to gain a better understanding of the fracture mechanism. Figure $8(a)$ shows a possible particle inclusion near the base of the beam. This may weaken one of the layers and result in a fracture. It is not clear if this is truly a defect in the dielectrics, or simply a piece of debris lying on the top surface. Figure $8(b)$ shows both the lateral crack and a lengthwise crack along the polysilicon edge as
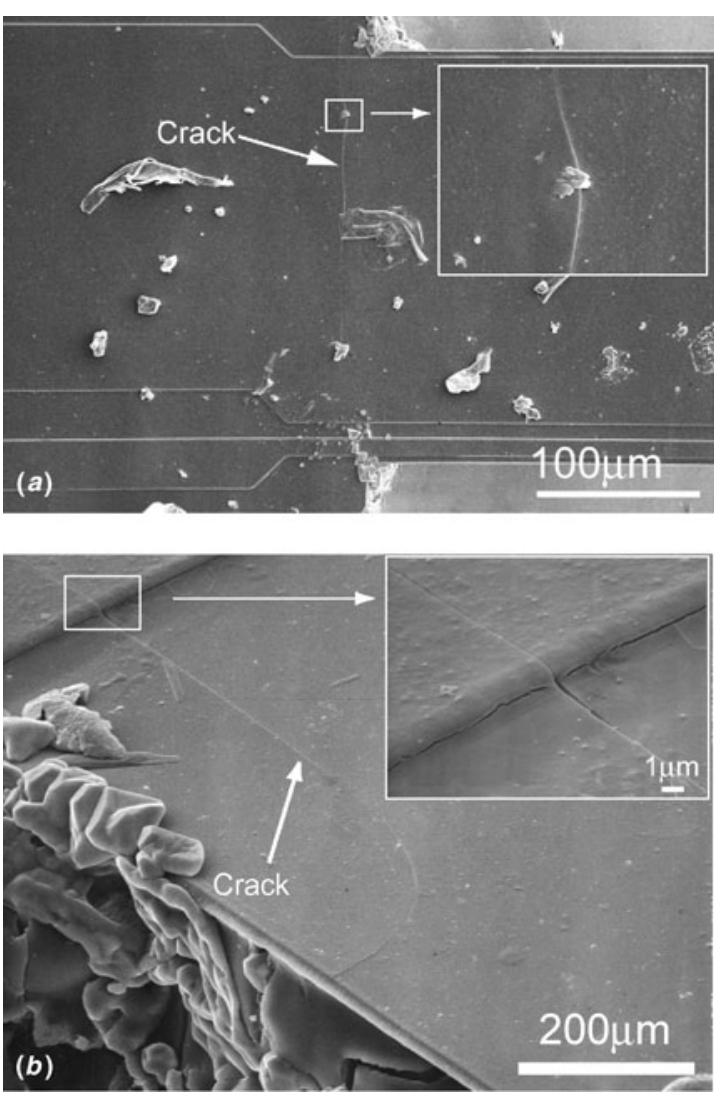

Figure 8. Possible failure mechanisms for the polysilicon cantilever beams. (a) Top view of beam shows partial crack running across beam width. Inset shows a possible particle inclusion. (b) The crack extends past the polysilicon (seen at top left), into the dielectrics, and terminates at the edge of the overhang. Inset shows intersection of lateral and lengthwise cracks at the edge of the polysilicon layer.

well. It is apparent that the lateral crack was greatest in width at the point where it crossed the step formed by the polysilicon, and where the two cracks intersected. The lateral crack continues on across the beam and disappears before it reaches the other side. In the other direction, the crack spreads through the dielectric overhang to its edge. The fact that the crack is widest at the point where it crosses the polysilicon border suggests that the stresses are greatest at that point, and possibly that the crack initiated at that point as well, spreading in both directions. Although this seems like the most likely reason for failure, other crack initiation points are also possible (e.g., at the edge of the dielectric overhang). Further study is necessary to accurately determine the crack's true origin.

Contact resistance at $1 \mathrm{kHz}$ (i.e., the magnitude of the contact impedance) was measured as a function of completed trials, and as a function of beam contact force (calculated), shown in figure 9 . The phase angle of the measured impedance was nearly zero, indicating an ohmic connection. Figure 9(a) shows that despite the treatment with the bovine albumen solution, the resistance was on the order of $1 \Omega$ and there was no significant change in resistance over time. In fact, SEM photographs show that the surface roughness of the contact actually decreased with time. This may be seen in figure 10 , which shows the electroplated gold pad before and after 1000 trials. The reduced roughness increases the effective contact area and may therefore decrease the resistance. However, it 

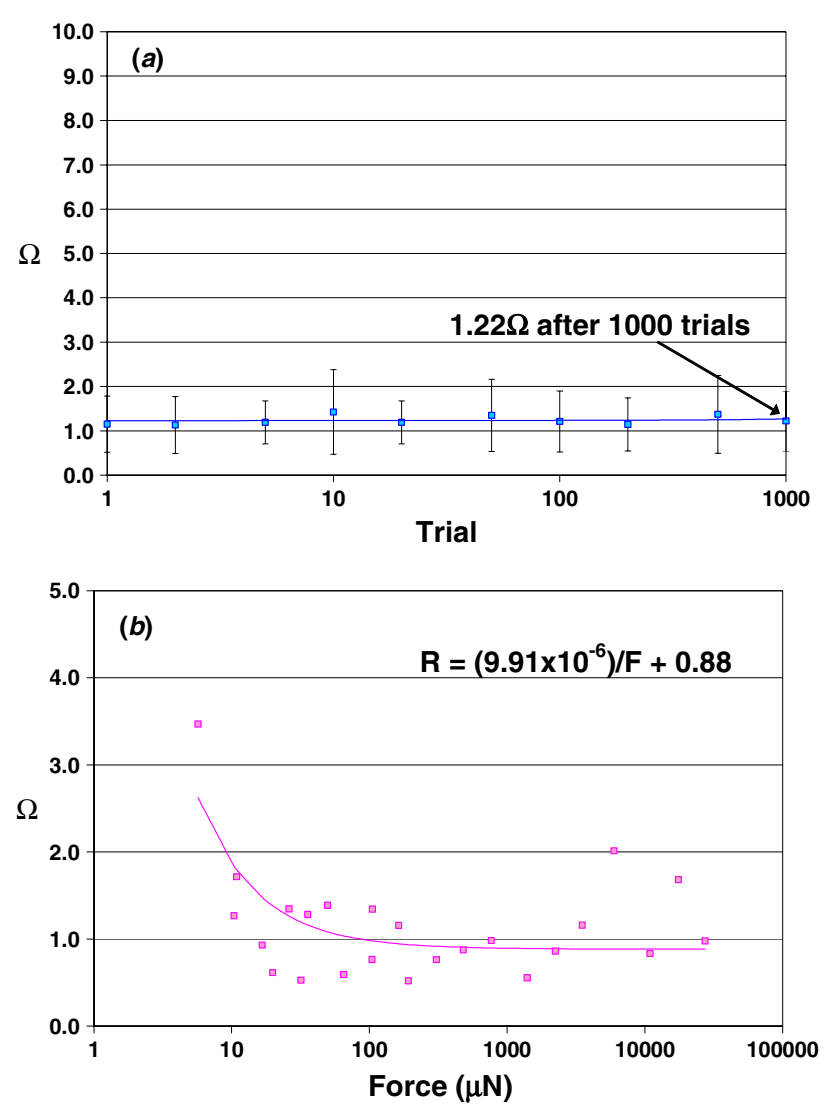

Figure 9. Contact resistance at $1 \mathrm{kHz}$. (a) Contact resistance as a function of number of trials performed, averaged over all beams. (b) Initial contact resistance as a function of applied force (force is calculated).

is suspected that this effect was either negligible, or that the decrease in resistance it provided was offset by other effects (debris, contamination, etc).

The contact surfaces were studied in more detail to determine what effect the repeated testing had on them. The observed decrease in roughness on the electroplated pad appears to be due to flattening of the gold asperities on the surface. This is interesting since the roughness of a contact typically tends to increase with usage due to mechanisms such as fretting and metal debris formation [26]. On the other hand, the corresponding gold bumps are initially very smooth (surface roughness: $R_{\mathrm{a}}=81 \mathrm{~nm}$ ), but their roughness increases slightly after 1000 trials $\left(R_{\mathrm{a}}=100 \mathrm{~nm}\right)$ (figure 11). It is possible that during the first 1000 trials, the gold bump is sufficiently smooth and hard enough to flatten out many of the irregularities on the electroplated gold pad, while some of the roughness of the pad is transferred to the surface of the gold bump. Continued testing may show that as the gold bump becomes even rougher, the roughness of the gold pad may actually start to increase as well. Thickness measurements on several electroplated pads were also performed before and after testing was done using a surface profilometer. It is possible that there could be some material loss due to friction, reducing the overall lifetime of the connector. A change in thickness of $-0.2 \pm 0.3 \mu \mathrm{m}$ was measured, which is to say that there was no statistically significant decrease in the electroplated gold thickness. This agrees with results others have obtained,
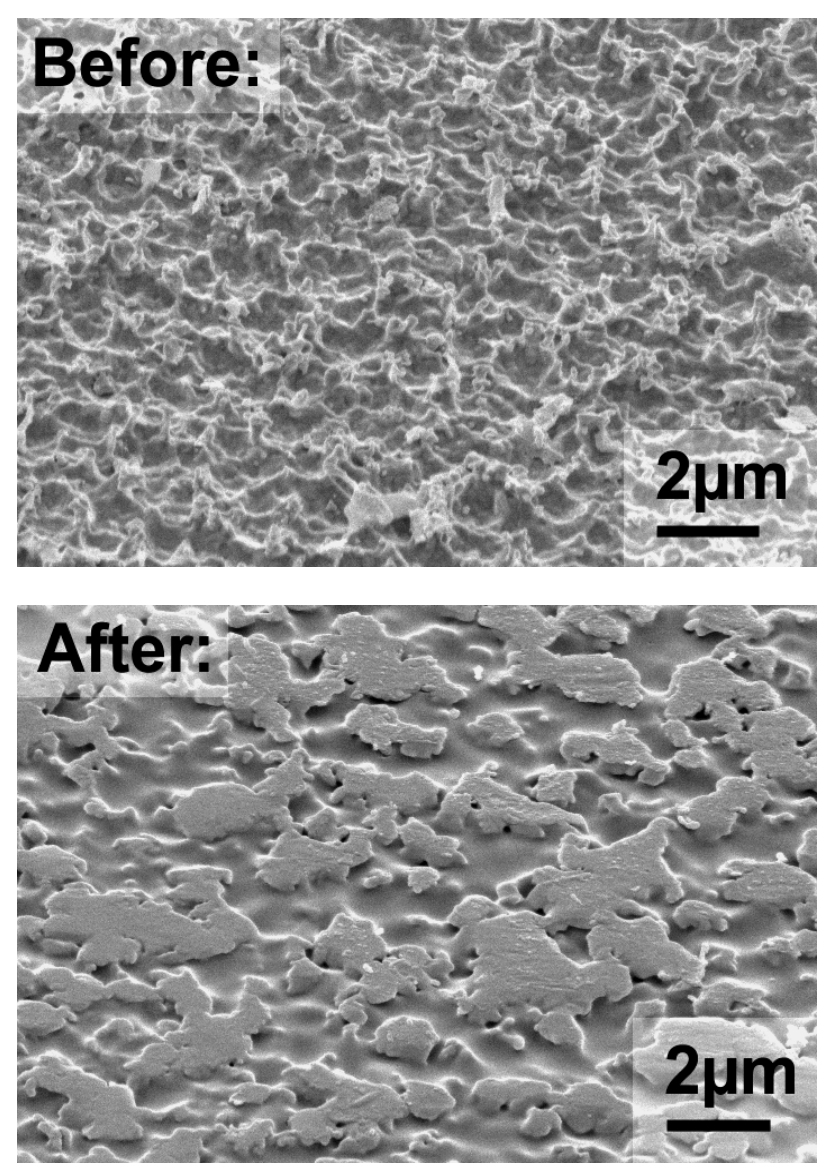

Figure 10. SEM micrographs of the electroplated gold pad on the cantilever beam, before and after 1000 trials.

which suggest that below 1000-10000 contact cycles there is no measurable deterioration $[27,28]$.

As mentioned earlier, a force of about $100 \mu \mathrm{N}$ was predicted to give a contact resistance of roughly 80-200 $\mathrm{m} \Omega$ [19]. For comparison, the average initial contact resistance for beams $300 \mu \mathrm{m}$ long and $160 \mu \mathrm{m}$ wide (calculated force: $105 \mu \mathrm{N}$ ) was $764 \mathrm{~m} \Omega$. After 1000 trials, beams of this type had an average final contact resistance of $1.598 \Omega$. This value is higher than expected, probably due to surface contamination. It is still quite low however, and remained low for all 1000 trials. Figure $9(b)$ gives a plot of the contact resistances as a function of the (calculated) force, after 1000 trials. An approximate fit of the data shows an inverse relationship between force and resistance. The overall resistance appears to level out at $883 \mathrm{~m} \Omega$ for $27.4 \mathrm{mN}$. For a beam size of $400 \mu \mathrm{m}$ long by $125 \mu \mathrm{m}$ wide, deflected $30 \mu \mathrm{m}$, the contact force is calculated to be $40.7 \mu \mathrm{N}$. Using the equation in figure $9(b)$, this gives a contact resistance of $1.13 \Omega$, sufficient for use in biomedical connector applications.

Future designs may incorporate even smaller beams. This could be made possible by insulating the beams with a single layer of LPCVD nitride on either side of the beam rather than the thicker, triple layer of dielectrics used on the beams described above. Thinner layers would make the beam more flexible and reduce stresses, ultimately allowing a shorter beam to deflect the required distance without fracturing. Currently, the minimum width of the contact pads and their minimum 

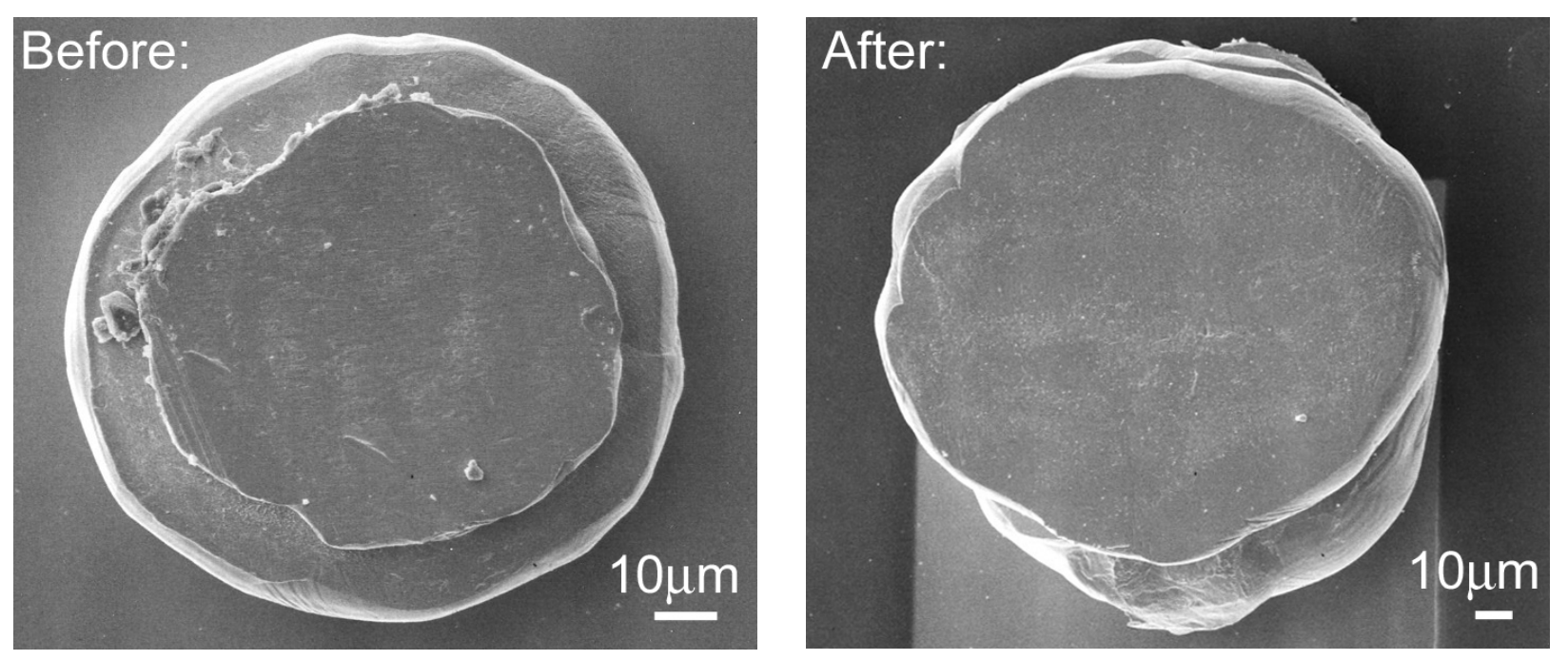

Figure 11. SEM micrographs of flattened gold ball bumps, before and after 1000 trials.
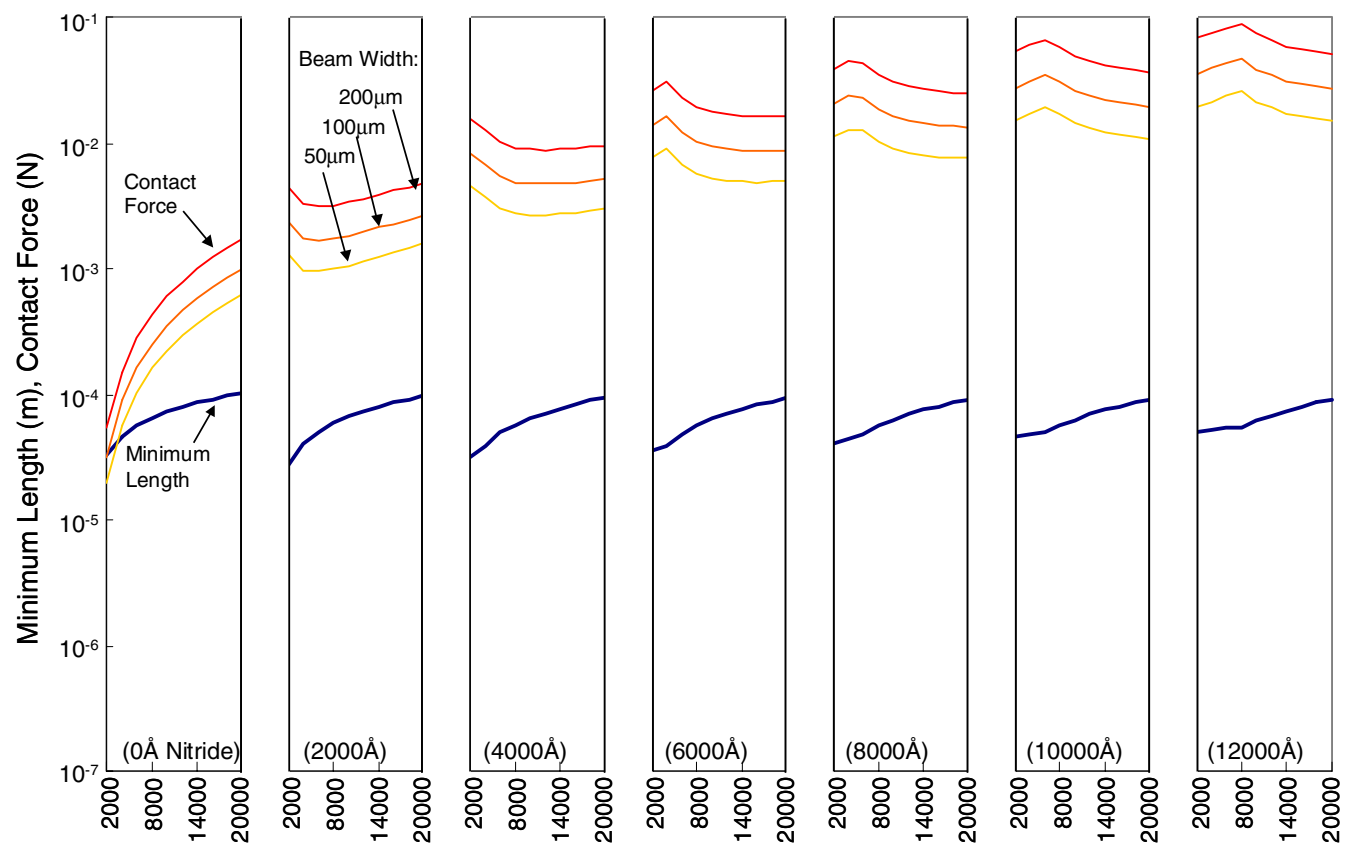

Polysilicon Thickness $(\AA)$

Figure 12. The minimum beam length and contact force at that length for a cantilever beam consisting of only nitride/poly/nitride, plotted as a function of polysilicon thickness. The thickness of each nitride layer is given at the bottom of each plot. Properties were calculated for beams having three widths: $60 \mu \mathrm{m}(50 \mu \mathrm{m}$ poly $), 110 \mu \mathrm{m}$ (100 $\mu \mathrm{m}$ poly) and $210 \mu \mathrm{m}$ (200 $\mu \mathrm{m}$ poly).

spacing is limited to $60 \mu \mathrm{m}$ and $60 \mu \mathrm{m}$, respectively. This is due to the method of aligning the two halves of the connector together in the proposed connector housing. For a beam $60 \mu \mathrm{m}$ wide, the width of the doped polysilicon should be $50 \mu \mathrm{m}$. The thicknesses of the layers must be chosen such that: (1) the minimum length of the beam is sufficiently small, preferably below $200 \mu \mathrm{m}$, (2) the contact force is greater than $100 \mu \mathrm{N}$ and (3) the resistance of the beam is not too large. Equations (11) and (13) were used to calculate the contact force and minimum length (respectively) for a nitride/poly/nitride beam, assuming a $30 \mu \mathrm{m}$ deflection (figure 12). If a polysilicon thickness of $3000 \AA$ and a nitride thickness of $2000 \AA$ (each side) were chosen, the calculated force would be $3.17 \mathrm{mN}$. The minimum calculated length would be $27.6 \mu \mathrm{m}$. Figure 13 shows the resistance of the beam as a function of polysilicon thickness. The resistance of the beam would be $33.1 \Omega$ for the given dimensions (assuming a resistivity of $1.2 \times 10^{-3} \Omega \mathrm{cm}$ ). If the correction factor of 2.6 were applied, the minimum length of the beam should be $70.8 \mu \mathrm{m}$. At this length the applied force for a $30 \mu \mathrm{m}$ deflection would be $187.2 \mu \mathrm{N}$ and the resistance would be $84.9 \Omega$. These beams exceed the above criteria and should be sufficient for high-density biomedical connector applications. 


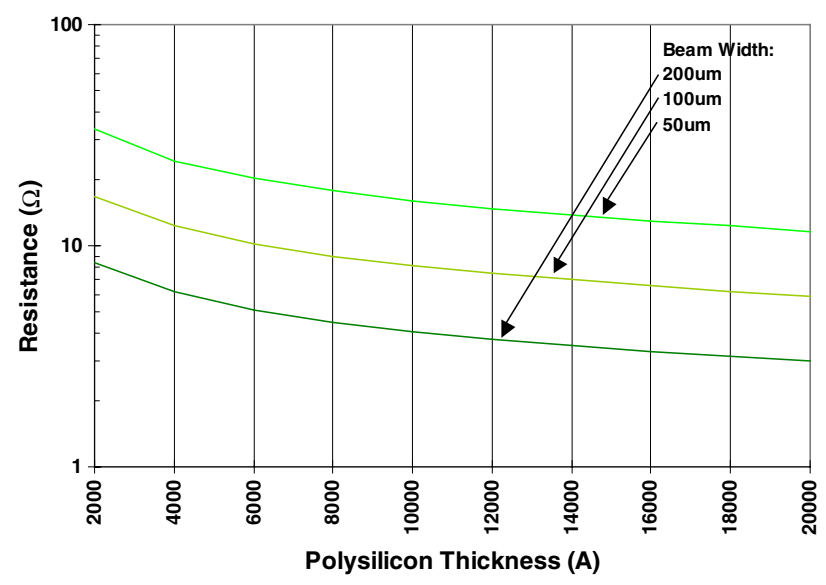

Figure 13. The resistance of a cantilever beam consisting of only nitride/poly/nitride, plotted as a function of polysilicon thickness, and assuming the thickness of each nitride layer is $2000 \AA$.

Resistance was calculated for beams having three widths: $60 \mu \mathrm{m}$ (50 $\mu \mathrm{m}$ poly), $110 \mu \mathrm{m}$ (100 $\mu \mathrm{m}$ poly) and $210 \mu \mathrm{m}$ (200 $\mu \mathrm{m}$ poly).

\section{Conclusion}

A high-density connector for use in biomedical applications has been proposed and a test was performed to determine the size of polysilicon beams that should be used. The data show that if the beams are to be compatible with the University of Michigan neural probe fabrication process, a choice of beam dimensions $400 \mu \mathrm{m}$ long by $125 \mu \mathrm{m}$ wide would give the smallest possible beam size (maximum density), while sufficiently ensuring that the beam will not break during its normal lifetime. However, beams may be safely made as small as $71 \mu \mathrm{m}$ long by $60 \mu \mathrm{m}$ wide if fewer dielectric layers were used. Furthermore, the contacts were shown to be low resistance having very little drift or deterioration with time, despite the presence of biological fluids. If the connector were used four times a day, 5 days a week, the beams should last roughly one year, sufficient for most chronically implanted probe preparations.

\section{Acknowledgments}

This research is supported by the National Institute on Deafness and Other Communication Disorders Grant DC04198, and National Institutes of Health Grant NIBIB EB00308.

\section{References}

[1] Zargari M, Leung J, Wong S S and Wooley B A 1999 BiCMOS active substrate probe-card technology for digital testing IEEE J. Solid-State Circuits 34 1118-35

[2] Soejima K, Kimura M, Shimada Y and Aoyama S 1999 New probe microstructure for full-wafer, contact-probe cards Proc.-Electronic Components and Technology Conf. (San Diego, USA) pp 1175-80

[3] Park S, Kim B, Kim J, Paik S, Choi B-D, Jung I, Chun K and Cho D-I D 2002 A novel 3D process for single-crystal silicon micro-probe structures J. Micromech. Microeng. 12 650-4

[4] Zhang Y, Zhang Y and Marcus R B 1999 Thermally actuated microprobes for a new wafer probe card J. Microelectromech. Syst. 8 43-9
[5] Akin T, Ziaie B, Nikles S A and Najafi K 1999 A modular micromachined high-density connector system for biomedical applications IEEE Trans. Biomed. Eng. 46 471-80

[6] Nikles S, Najafi K, Bradley R and Bledsoe S 2001 Reliability and contact resistance of polysilicon beam leads for use in a high-density connector Proc. IEEE Micro Electro Mechanical Systems (MEMS) (Interlaken, Switzerland) pp 64-7

[7] Bradley R M, Cao X G, Akin T and Najafi K 1997 Long term chronic recordings from peripheral sensory fibers using a sieve electrode array J. Neurosci. Methods 73 177-86

[8] Bai Q and Wise K D 2001 Single-unit neural recording with active microelectrode arrays IEEE Trans. Biomed. Eng. 48 911-20

[9] Stieglitz T, Beutel H and Meyer J U 2000 'Microflex' a new assembling technique for interconnects J. Intell. Mater. Syst. Struct. 11 417-25

[10] Jamieson B, Buzsaki G and Wise K 200096 channel silicon neural recording probe with integrated buffers Ann. Biomed. Eng. 28 (Suppl. 1) S-112

[11] Gingerich M D, Wiler J A and Wise K D 1999 Use of an active microelectrode array for stimulation and recording in the central nervous system Ann. Int. Conf. IEEE Engineering in Medicine and Biology Proc. (Atlanta, USA) p 471

[12] Najafi K, Wise K D and Mochizuki T 1985 A high-yield IC-compatible multichannel recording array IEEE Trans. Electron Devices 32 1206-11

[13] Hetke J F, Lund J L, Najafi K, Wise K D and Anderson D J 1994 Silicon ribbon cables for chronically implantable microelectrode arrays IEEE Trans. Biomed. Eng. 41 314-21

[14] Edell D J, Gleason K K, Larson B C, Sexton S, Vannaria C, Lewis H and Winder E J 1999 Insulating biomaterials Final Quarterly Progress Report (1999) \#N01-NS-62350, Neural Prosthesis Program, NIH, NINDS

[15] Johansson S, Ericson F and Schweitz J-Å 1989 Influence of surface coatings on elasticity, residual stresses, and fracture properties of silicon microelements J. Appl. Phys. $65122-8$

[16] Ericson F and Schweitz J-A 1990 Micromechanical fracture strength of silicon J. Appl. Phys. 68 5840-4

[17] Schmitt G, Schultze J-W, Fassbender F, Buss G, Lueth H and Schoening M J 1999 Passivation and corrosion of microelectrode arrays Electrochim. Acta 44 3865-83

[18] Gere J M and Timoshenko S 1997 Mechanics of Materials 4th edn (Boston: PWS Publishing Co.) xvi, 912 ill

[19] Hyman D and Mehregany M 1999 Contact physics of gold microcontacts for MEMS switches IEEE Trans. Compon. Packag. Technol. 22 357-64

[20] Kovacs G T A 1998 Micromachined Transducers Sourcebook (Boston: WCB/McGraw-Hill) xx, 911, E913 ill

[21] C L Muhlstein and S B Brown (ed) 2001 Mechanical Properties of Structural Films (ASTM Special Technical Publication) (W Conshohocken, PA: ASTM) vii, 333 ill

[22] Greek S, Ericson F, Johansson S and Schweitz J-Å 1997 In situ tensile strength measurement and Weibull analysis of thick film and thin film micromachined polysilicon structures Thin Solid Films 292 247-54

[23] Sharpe W N Jr, Yuan B, Vaidyanathan R and Edwards R L 1997 Measurements of young's modulus, poisson's ratio, and tensile strength of polysilicon Proc. IEEE Micro Electro Mechanical Systems (MEMS) (Nagoya, Japan) pp 424-9

[24] Fan L-S, Muller R S, Yun W, Howe R T and Huang J 1990 Spiral microstructures for the measurement of average strain gradients in thin films Proc. IEEE Micro Electro Mechanical Systems: An Investigation of Micro Structures, Sensors, Actuators, Machines and Robots (Napa Valley, CA, USA) pp 177-81

[25] Schweitz J-Å and Ericson F 1999 Evaluation of mechanical materials properties by means of surface micromachined structures Sensors Actuators A 74 126-33 
[26] P G Slade (ed) 1999 Electrical engineering and electronics Electrical Contacts: Principles and Applications vol 105 (New York: Marcel Dekker) xxi, 1073 ill

[27] Bryant M D 1994 Assessment of fretting failure models of electrical connectors Electrical Contacts, Proc. Annu. Holm Conf. on Electrical Contacts pp 167-75

[28] Yang Q, Zhao Z, Engel P A and Constable J H 1995 Impact wear of multiplated connectors in the presence of electrical current Electrical Contacts, Proc. Annu. Holm Conf. on Electrical Contacts pp 135-46

[29] Halg B 1990 On a nonvolatile memory cell based on micro-electro-mechanics Proc.-IEEE Micro Electro Mechanical Systems: An Investigation of Micro Structures, Sensors, Actuators, Machines and Robots (Napa Valley, CA, USA) pp 172-6
[30] J F Shackelford and W Alexander (ed) 2001 CRC Materials Science and Engineering Handbook 3rd edn (Boca Raton, FL: CRC Press) p 1949

[31] Petersen K E 1978 Dynamic micromechanics on silicon: techniques and devices IEEE Trans. Electron Devices ED-25 1241-50

[32] Kim M T 1996 Influence of substrates on the elastic reaction of films for the microindentation tests Thin Solid Films $\mathbf{2 8 3}$ $12-6$

[33] Tabata O, Kawahata K, Sugiyama S and Igarashi I 1989 Mechanical property measurements of thin films using load-deflection of composite rectangular membranes Sens Actuators 20 135-41

[34] Lee S, Cho C, Kim J, Park S, Yi S, Kim J and Cho D-i D 1998 Effects of post-deposition processes on polysilicon young's modulus J. Micromech. Microeng. 8 330-7 